\title{
A generalized additive model to disentangle age and diagnosis-specific cohort effects in psychological and behavioral outcomes in people living with HIV: the French cross-sectional ANRS- VESPA2 survey
}

Luis Sagaon-Teyssier ${ }^{1,2^{*}}$ D, Antoine Vilotitch ${ }^{1,2}$, Marion Mora ${ }^{1,2}$, Gwenaëlle Maradan ${ }^{1,2}$, Valérie Guagliardo ${ }^{1,2}$, Marie Suzan-Monti ${ }^{1,2}$, Rosemary Dray-Spira ${ }^{3,4}$, Bruno Spire ${ }^{1,2}$ and VESPA2 study group

\begin{abstract}
Background: Unlike their younger counterparts, some of today's older HIV patients were diagnosed before the advent of highly active antiretroviral therapy (HAART). The psychosocial and behavioral outcomes of people living with HIV (PLWH) have been widely studied, and associated factors are well known. However, their evolution both in terms of age and diagnosis-specific cohort effects is not well understood.

Methods: Data from the ANRS-VESPA2 cross-sectional survey, representative of French PLWH, were used to investigate whether psychosocial and behavioral outcomes such as quality of life, need for support and HIV status disclosure, evolve under both the influence of patients' age and diagnosis-specific cohort effects. A semi-parametric generalized additive model (GAM) was employed. The physical and mental components of health-related quality of life, the need for material and moral support, and HIV-status disclosure, constituted our outcomes.

Results: Non-linear diagnosis-specific cohort effects were found for physical and mental QoL and HIV-status disclosure. Overall, physical QoL was better in recently diagnosed patients than in those diagnosed in the early 1980s. An increasing influence of diagnosis-specific cohort effects between 1983 and 1995 was observed. No cohort effects were noticeable between 1996 and 2000, while an increasing influence was apparent for patients diagnosed with HIV from 2000 to 2011 (year of study). For mental QoL, the only increase was observed in participants diagnosed with HIV between 1983 and 2000. The relationship between diagnosis-specific cohort effects and HIV status disclosure was negative overall: participants diagnosed after 2000 were much less likely to disclose than those diagnosed before 1995. The effect of age was significantly associated with all outcomes, with a non-linear influence on mental QoL and with the need for material/moral support.

(Continued on next page)
\end{abstract}

\footnotetext{
* Correspondence: luis.sagaon-teyssier@inserm.fr

${ }^{1}$ Aix Marseille Univ, INSERM, IRD, SESSTIM, Sciences Economiques \& Sociales

de la Santé \& Traitement de I'Information Médicale, 27 Bd Jean Moulin,

13385 Marseille Cedex 5, France

2ORS PACA, Southeastern Health Regional Observatory, 27 Bd Jean Moulin,

13385 Marseille Cedex 5, France

Full list of author information is available at the end of the article
}

(c) The Author(s). 2019 Open Access This article is distributed under the terms of the Creative Commons Attribution 4.0 International License (http://creativecommons.org/licenses/by/4.0/), which permits unrestricted use, distribution, and

reproduction in any medium, provided you give appropriate credit to the original author(s) and the source, provide a link to the Creative Commons license, and indicate if changes were made. The Creative Commons Public Domain Dedication waiver (http://creativecommons.org/publicdomain/zero/1.0/) applies to the data made available in this article, unless otherwise stated. 
(Continued from previous page)

Conclusions: Psychosocial and behavioral outcomes are complex processes which can be explained in different ways by a combination of the clinical and social contexts which PLWH are exposed to at the time of diagnosis, and by developmental characteristics. A greater understanding of these processes could inform healthcare policymaking for specific HIV generations and different HIV age groups.

Keywords: Age, Cohort effects, Quality of life, Material and moral support, HIV-status disclosure, Semi-parametric GAM

\section{Background}

The psychosocial and behavioral outcomes of people living with HIV (PLWH) have been widely studied, and associated factors are well known. However, no study to date has simultaneously investigated the influence which both age and human immunodeficiency virus (HIV) diagnosis-related cohort effects may have on these outcomes, specifically because of the methodological difficulties arising from their linear dependency. Disentangling these two influences from one another is important in order to understand whether psychosocial and behavioral outcomes of PLWH are processes driven by individual-related characteristics such as age, and/or by contextual-related aspects. However, this is methodologically challenging for several reasons: i) the complex composition of the population of PLWH in terms of age and year of diagnosis, ii) the complex evolution of HIV care, which has seen improvements in diagnosis, treatment and health care programs lead to HIV becoming a chronic disease, and iii) the relationship between the timing of these improvements and aging. More specifically, unlike their younger HIV counterparts, some of today's older patients were diagnosed and treated before the advent of highly active antiretroviral therapy (HAART) with serious negative consequences on their health-related quality of life due to the toxicity of older drugs such as stavudine, zidovudine and nevirapine [1]. In addition, aging with HIV is not only related to clinical aspects such as antiretroviral-related side effects, comorbidities and pain, but also to stigma [2,3]. Furthermore, mental and physical health may be affected by the isolation of PLWH and the consequent difficulties they encounter with regard to HIV disclosure, especially for older people $[4,5]$. In this study, we argue that variations in psychosocial and behavioral outcomes among PLWH can be attributed not only to individual differences but also to the different clinical and social contexts which they were confronted with at the time of HIV diagnosis, represented by diagnosis-specific cohort effects.

While studies on psychosocial and behavioral outcomes among PLWH often focus on the relationship between age and outcomes, to date the question of diagnosis-specific cohort effects has only been studied indirectly, by specifying a variable accounting for the time elapsed since HIV diagnosis. No study has ever simultaneously explored the influence of both of these factors in the same model. In terms of patient's age, existing literature has suggested a modest or null effect on quality of life (irrespective of the instrument used HAT-HRQL, WHOQOL, SF-36 or SF-12) [6-10]. However, contrasting results have been found regarding its effect on disclosure, with one study indicating a relatively higher probability of disclosure in older PLWH [11], while another reported a significant effect in bivariate analysis which was no longer significant in multivariate analysis [12]. In studies using a more detailed definition of disclosure - one where the degree of disclosure was specified (i.e., broad, selective or no disclosure) [13, 14], and another where the persons to whom participants disclosed were specified (i.e., partner, family, friend, colleague, etc.) [9] - no effect of age on disclosure was observed. In terms of diagnosis-specific cohort effects on disclosure, no study to date has yet addressed this relationship, although there is evidence suggesting that the time elapsed since HIV diagnosis is positively related to disclosure [15], implying that patients in newer cohorts are less likely to disclose their HIV status.

In France, quality of life (QoL) analyses in the crosssectional study ANRS-VESPA1 (2003) noted that older PLWH were more likely to report an acceptable physical quality of life (PQoL), whereas no significant age effect was found for mental quality of life (MQoL). However, when specifically distinguishing between PLWH diagnosed before/after 1996 (i.e., reflecting the pre-HAART and HAART eras), the results from the same data revealed no significant effect either for PQoL or MQoL [16]. Analyses of data from the ANRS-VESPA2 crosssectional study (2011) showed that age was negatively associated with $\mathrm{PQoL}$ but positively associated with MQoL. However, diagnosis-specific cohort effects were not analyzed with these data, and only a negative association was found between time since HIV diagnosis and both QoL dimensions [17].

One of the difficulties of simultaneously studying age and diagnosis-specific cohort effects is linked to the strong potential linear dependency between these two explanatory factors. Although some studies attempt to address this issue [18-22], most (including those on HIV) do it only superficially. Indeed, authors often circumvent this linear dependency either by aggregating or 
stratifying age and/or cohort in categories, resulting in the waste of important information $[23,24]$. The objective of the present paper was to implement a tailored methodological framework to assess the extent to which the patterns of QoL, of material/moral support needs, and of HIV-status disclosure are related to diagnosisspecific cohort effects, to age, and to a combination of both these factors.

\section{Methods}

\section{Study design and participants}

Data were used from the ANRS-VESPA2 survey (ANRS is the French National Agency of research on AIDS and viral hepatitis; VESPA2 is the acronym for "VIH: Enquête sur les Personnes Atteintes"), which is representative of PLWH followed up in 2011 in 73 French care units with caseloads of more than $100 \mathrm{HIV}+$ patients. Eligibility criteria were $>18$ years old, diagnosed as $\mathrm{HIV}+$ and living in France for at least 6 months. The 3022 patients included in the sample provided information about their living conditions including socio-demographic, economic, psychosocial and behavioral aspects, in a face-to-face interview. A self-administered questionnaire collecting other patient information was used to assess QoL, self-perception of health status, and quality of HIV care received. HIV care staff provided medical patient-related information about key indicators of HIV, comorbidities, treatments and hospital-related characteristics (see Dray-Spira et al. [25]). The survey was approved by the French ethical committee (CCTIRS, 20/01/2010) and the Commission for data protection (CNIL, Decision DR-2010-368, 06/12/2010).

\section{Psychosocial and behavioral outcomes}

The PQoL and MQoL scores for health related quality of life (HRQL) were calculated using the SF-12 scale included in the self-administered questionnaire [26]. These scores are continuous variables ranging from 0 to 100 , with higher scores denoting better HRQL. To assess respondents' need for material/moral support, two dichotomous variables were constructed as follows: 1 = support needed in the previous 12 months (whether received or not), and $0=$ no support needed. Finally, a dichotomous variable indicated whether a patient had disclosed $(=1)$ or not $(=0)$ his/her HIV-status to at least one relative or close acquaintance.

\section{Statistical analysis}

Descriptive statistics were performed for the outcomes considered in this study, and potential explanatory factors were selected from bivariate analysis using Fisher's test and median tests for categorical and continuous variables, respectively. A semi-parametric generalized additive model (GAM) was implemented for each outcome with the following form:

$$
g(\text { mean outcome })=\alpha+\beta X+f_{1}(\text { cohort })+f_{2}(\text { age })
$$

In this expression, $\alpha+\beta \mathrm{X}$ is the parametric portion of the model where $\alpha$ is the intercept and $\beta$ is the vector of parameters associated with the set of explanatory variables $\mathrm{X}$. The non-parametric part of expression (1) is formed by $f_{1}($. and $\mathrm{f}_{2}($.$) , which are smooth functions for diagnosis-specific$ cohort and age effects, respectively. These two functions describe the relationship between these explanatory factors and the studied outcomes. The functions are associated with estimated degrees of freedom (EDF) that indicate whether the relationship is linear $(\mathrm{EDF}=1)$ or non-linear (EDF $>1)$. One of the main advantages of the GAM implemented in this study is the possibility to address the issue of linear dependency (i.e. collinearity) [27] between diagnosis-specific cohort and age effects which often impedes their simultaneous estimation. Estimations for the two factors' effects on PQoL and MQoL scores were carried out by specifying a linear structure (i.e., the $\mathrm{g}($.) was the identity link function), whereas for the need for material/ moral support and HIV disclosure, a probit function was used (i.e., g(.) was the probit link function). Sociodemographic, socioeconomic and/or clinical-related patient characteristics were controlled for in the parametric portion of the model. $\mathrm{R}$ software was used to perform all the statistical analyses in this article [28], and the "mgcv" package for GAM estimation [29].

\section{Results}

PQoL and MQoL scores were computed for the 2267 (out of 3022) participants who answered all 12 items of the SF-12 scale measuring HRQL (i.e., a response rate of 75\%) included in the self-administered questionnaire. Median scores for PQoL and MQoL were 48.4 IQR [40.6-54.6] and 45.1 IQR [33.7-53.2], respectively. With regard to the need for material and moral support, of the 3006 participants for whom information was available, 55.9 and $80.6 \%$, respectively, declared they needed support. Finally, 3016 participants declared they had disclosed their HIV status to at least one relative or close acquaintance.

\section{Parametric portion of the model}

Parametric estimates are presented in Table 1. PQoL scores were lower for women (coeff $=-1.3,95 \%$ CI $[-2.2 ;-0.5]$ ), for Sub-Saharan African immigrants (coeff $=-2.6,95 \% \mathrm{CI}$ [-3.7;-1.5]), for participants perceiving both difficult financial situations (coeff $=-2.5,95 \%$ CI $[-3.3 ;-1.6])$ and care-related discrimination $\quad($ coeff $=-3.1, \quad 95 \%$ CI $\quad[-$ 4.3;-1.9]), for patients who had experienced AIDS-defining malignancies $($ coeff $=-1.8,95 \%$ CI $[-2.6 ;-1.0])$ and for HCV co-infected patients (coeff $=-1.7$, 95\% CI [-2.7; $0.7]$ ). On the contrary, employed patients (coeff $=2.9,95 \%$ CI $[2.1 ; 3.6]$ ) and those with a high level of education (coeff $=1.3$, 95\% CI $[0.1 ; 2.4]$ ) had higher PQoL scores. Higher 
scores for MQoL were found for Sub-Saharan African immigrants (coeff $=5.0,95 \%$ CI $[3.6 ; 6.4]$ ), married and cohabitating participants $($ coeff $=1.9,95 \%$ CI $[1.0 ; 2.9])$, participants with a positive perception of their financial situation (coeff = $1.7,95 \%$ CI $[0.5 ; 3.0])$, and those who had never experienced AIDS-defining malignancies (coeff $=1.6,95 \% \mathrm{CI}[0.6,2.7]$ ).

Probit estimates show that need for material support was more likely in women (coeff $=0.4,95 \%$ CI $[0.2 ; 0.6]$ ), Sub-Saharan African immigrants (coeff $=0.8,95 \%$ CI [0.5;1.1]), and participants with children (coeff $=0.295 \% \mathrm{CI}$ $[0.0 ; 0.4])$. Participants reporting unfavorable socioeconomic characteristics were more likely to need material support, specifically those who declared a difficult financial situation (coeff $=1.7,95 \%$ CI $[1.4 ; 1.9])$ and beneficiaries of free universal health coverage (coeff $=0.8,95 \%$ CI $[0.4 ; 1.1]$ ), which is allocated only to people on low income and those unemployed in France. On the contrary, married (coeff $=-$ $0.6,95 \%$ CI $[-0.8 ;-0.4])$ and employed (coeff $=-0.5,95 \%$ CI [- 0.7;-0.3]) participants were less likely to need material support. Participants' perception of care-related discrimination was associated with an increased probability of needing material support (coeff $=0.5,95 \%$ CI $[0.2 ; 0.8]$ ), whereas no health-related factors were associated with this outcome. Women (coeff $=1.1,95 \% \mathrm{CI}[0.8 ; 1.4])$ and those with difficult financial situations (coeff $=0.7,95 \% \mathrm{CI}$ $[0.5 ; 1.0])$ were more likely to need moral support. The probability of needing moral support was also higher in MSM (coeff $=0.4,95 \% \mathrm{CI}[0.2 ; 0.7]$ ) and HCV co-infected patients (coeff $=0.6,95 \% \mathrm{CI}[0.3 ; 0.9]$ ).

The last column in Table 1 shows the probit estimation for HIV-status disclosure. This outcome was associated with sociodemographic characteristics. Women (coeff $=0.6,95 \%$ CI $[0.2 ; 1.1]$ ), married participants (coeff $=1.4,95 \%$ CI $[0.9 ; 1.8]$ ) were more likely to disclose their HIV status. MSM also tended to be more likely to disclose. Finally, Sub-Saharan African immigrants (coeff = $-1.1,95 \%$ CI [-1.5;-0.6]) were less likely to disclose.

Fixed-effects for hospitals were specified for all models in order to control for hospital-related heterogeneity in our outcomes (results not-shown). However, heterogeneity appeared to be individual-related rather than hospital-related as fixed-effects were not significant.

\section{Non-parametric portion of the model: diagnosis-specific cohort effects and age effect}

The effect of age and of diagnosis-specific cohort effects were assessed non-parametrically over the five outcomes analyzed in this article and are presented at the bottom of Table 1. The GAM estimation indicated, through the significant EDF associated with diagnosis-specific cohort effects, that the time at which participants were diagnosed with HIV influenced MQoL $(\mathrm{EDF}=2.2, p<0.01)$, PQoL $(\mathrm{EDF}=3.2, p<0.05)$ and HIV-status disclosure $(\mathrm{EDF}=3.7, p<0.01)$. More specifically, diagnosis-specific cohort effects were nonlinear, with large fluctuations over time being observed, principally for the latter two outcomes as shown in Fig. 1a and e, respectively. Overall, PQoL was better in patients recently diagnosed than in those diagnosed in the early 1980s. An increasing influence of diagnosis-specific cohort effects between 1983 and 1995 was observed. No cohort effects were noticeable between 1996 and 2000, while an increasing influence was apparent for patients diagnosed with HIV after 2000. The influence of diagnosis-specific cohort effects on MQoL fluctuated less (Fig. 1b), with the only increase being observed in participants diagnosed with HIV between 1983 and 2000. Patients diagnosed after this period did not differ in terms of MQoL. Finally, the relationship between diagnosis-specific cohort effects and HIV status disclosure was negative overall: participants diagnosed after 2000 were much less likely to disclose than those diagnosed before 1995. Between 1995 and 2000 no diagnosis-specific cohort effect on HIV status disclosure was observed (Fig. 1e).

The effect of age was significant for the 5 outcomes analyzed. It was linear for both PQoL $(\mathrm{EDF}=1.1, p<$ 0.01 ) (see Fig. 1a) and HIV status disclosure $(E D F=1.4$, $p<0.01$ ), but non-linear with large fluctuations for MQoL $(E D F=6.2, p<0.01$ ) (see Fig. 1b), the need for material support (EDF $=7.1, p<0.01$ ) and for moral support $(\mathrm{EDF}=8.6, p<0.01)$. With respect to MQoL, Fig. $1 \mathrm{~b}$ shows a decrease for those between 18 and 30 years old, followed by an increase for those between 31 and 64 years old, and another decrease for those 65 and older. The effect of age on the need for material support and for moral support was similar, although more pronounced for the former (Fig. 1c and d). More specifically the probability of needing material or moral support decreased in those between 20 and 65 years old, then increased in those up to 80 years of age before it started to decrease again. Finally, a negative linear relationship between age and the probability of disclosing HIV status was found, with older participants being more likely to disclose than younger patients (Fig. 1e).

\section{Discussion}

Our results suggest that PQoL is primarily driven by diagnosis-specific cohort effects, which may be attributable to exposure to different clinical contexts over time. In contrast, the evolution of MQoL appears to be an individual process which changes with age. HIV status disclosure was driven by the combined effect of age at the time of diagnosis and the year of diagnosis. Our semi-parametric generalized additive model on data from the ANRS-VESPA2 study confirmed the importance and value of disentangling diagnosis-specific cohort effects from age effects in order to understand the interplay between contextual and developmental influences on the evolution of psychosocial and 


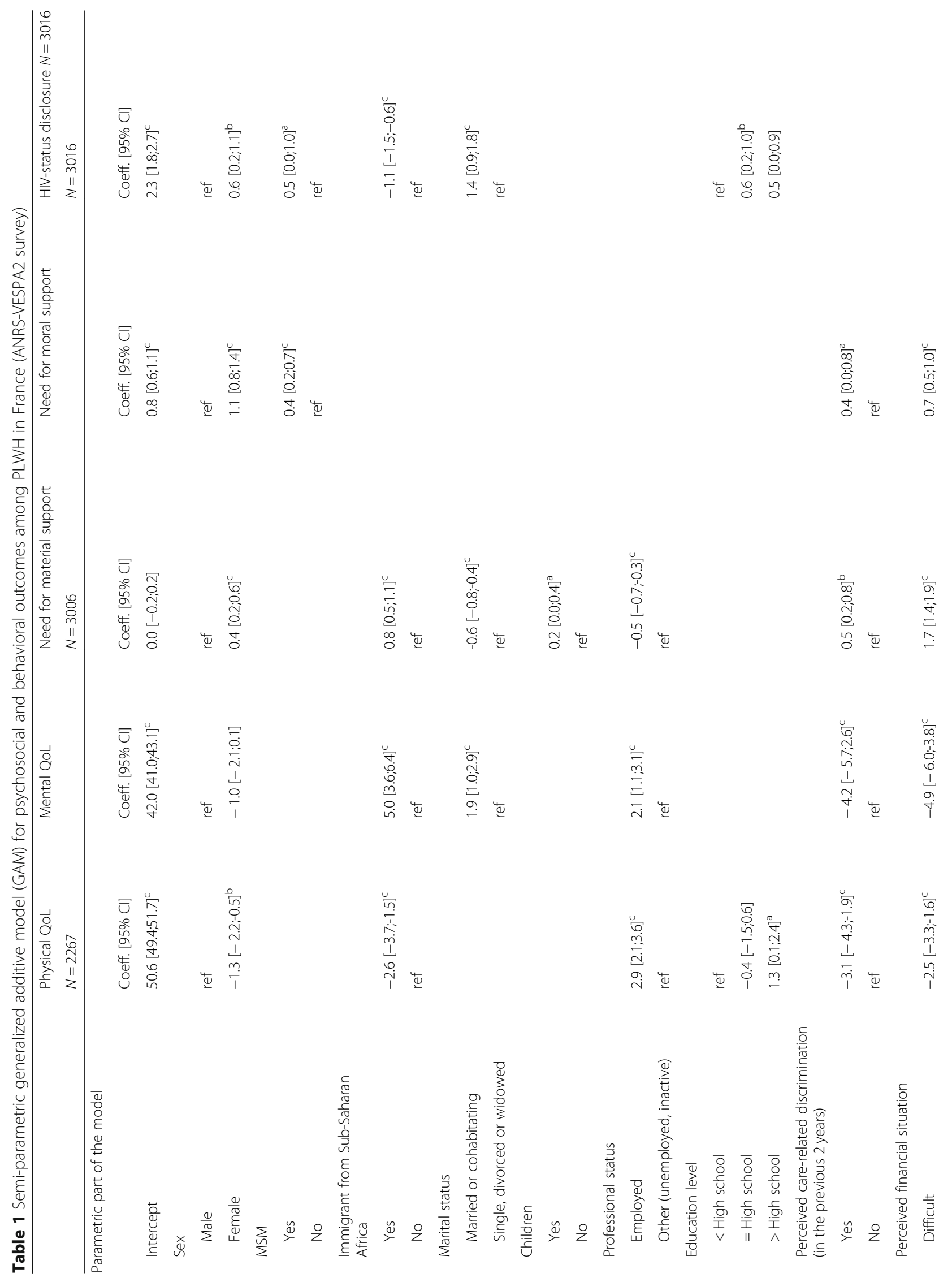




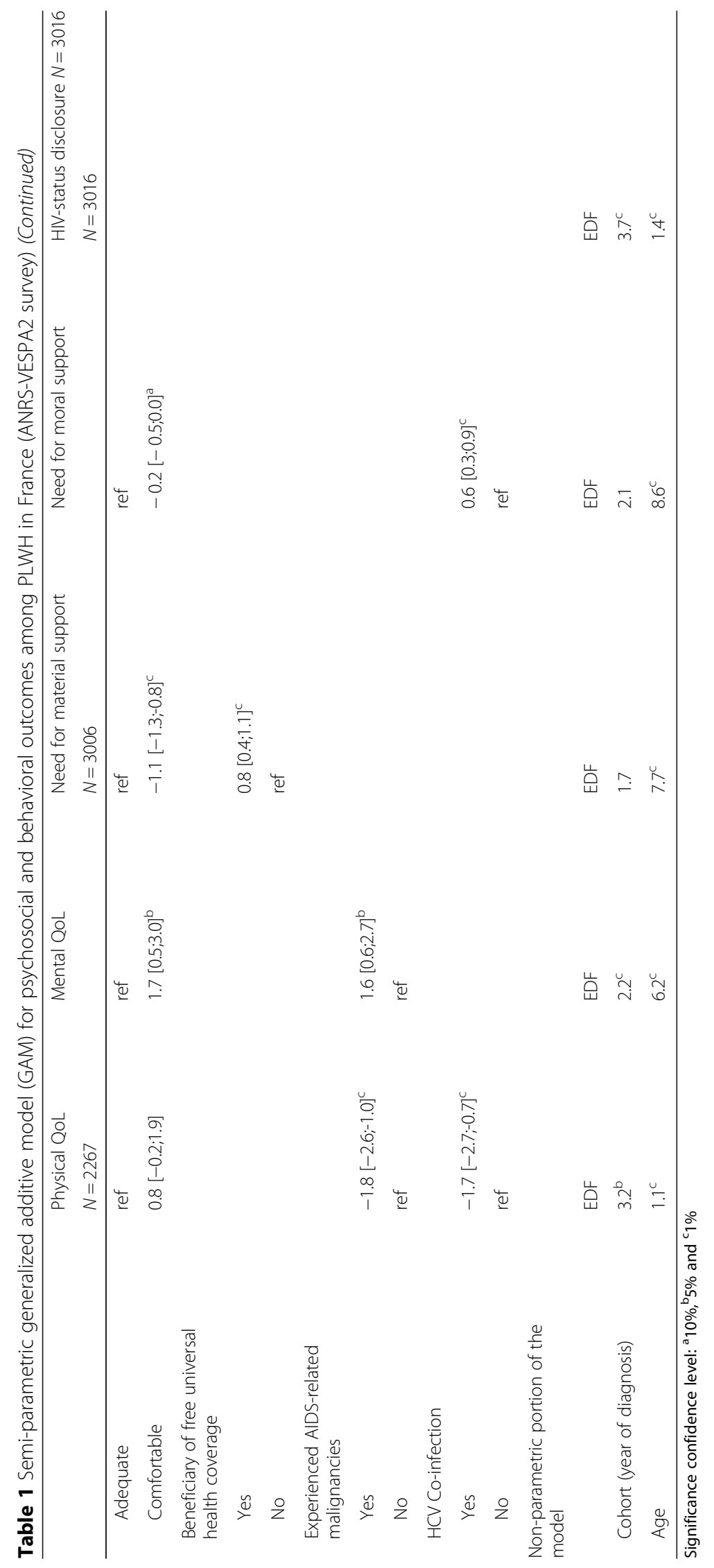


a) Physical quality-of-life

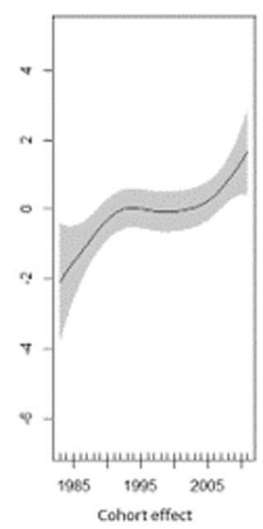

c) Need for material support
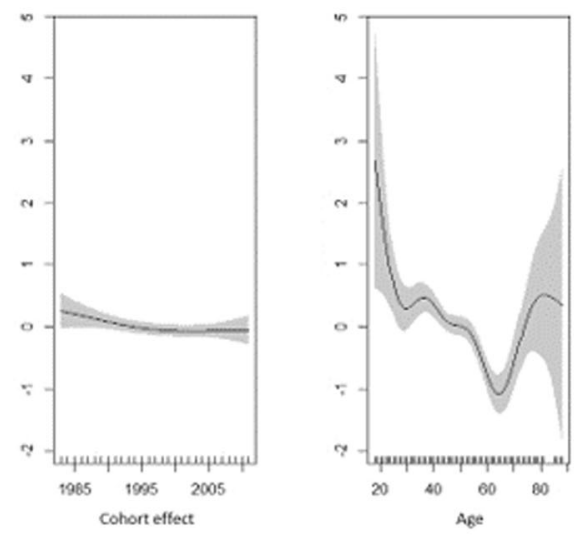

e) HIV status disclosure

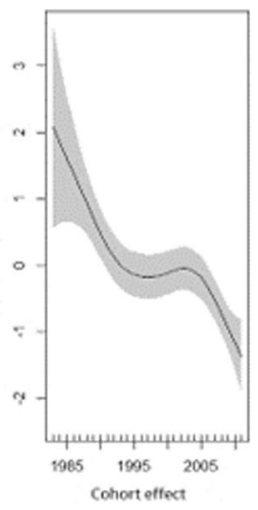

b) Mental quality-of-life
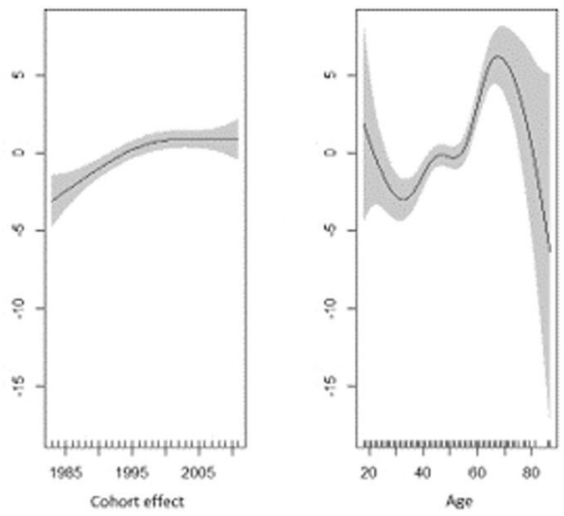

d) Need for moral support
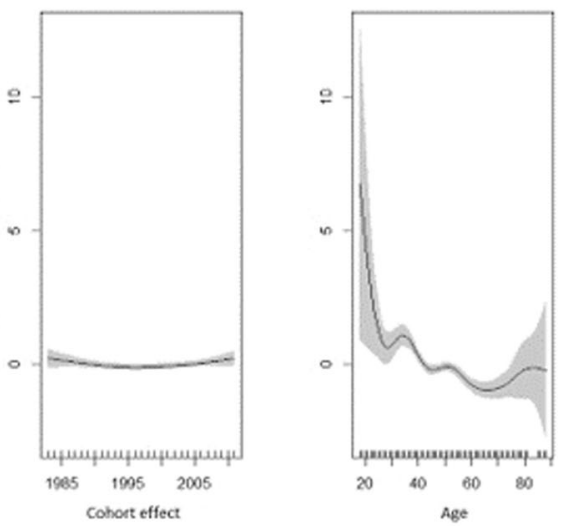

Fig. 1 Non-parametric estimation of diagnosis-specific cohort effects and the effect of age

behavioral outcomes among PLWH. The particular evolution of the need for moral and material support shows that these outcomes are individual processes that differ from one another only in terms of age. In contrast, with regard to QoL, the PQoL and MQol processes appear to be more complex and are the result of the combination of both diagnostic-specific cohort effects (for PQoL) and the effect of age (MQoL).

Improved survival rates, thanks to the efficiency of HAART, have led to aging with HIV becoming an 
important research subject, from both biological and clinical points of view. [30]. Indeed some processes are accelerated (e.g., in the immunological system), whereas others (e.g., organ-specific processes) are more accentuated than accelerated, leading to morbidity [31]. The literature also notes that PLWH are more likely to experience psychiatric problems and have relatively higher suicide tendencies, especially those aged 65 and over [32]. However, much less is known about the association between aging and psychosocial/behavioral outcomes in PLWH, and the evolution of these outcomes in terms of the social and care contexts (with diagnostic-specific cohort effects being proxies) at the time of diagnosis.

The positive diagnostic-specific cohort effects found for PQoL and MQoL are in line with existing literature and may be linked to improvements in treatment efficacy and tolerability as well as increased effectiveness of tailored HIV care programs that reflect the different care contexts PLWH experienced depending on the year in which they were diagnosed [33]. New therapeutic HIV regimens have been associated with better quality of life through improved physical health [34-36]. Nevertheless, this positive diagnosis-specific cohort effect is countered by the fact that PQoL decreases as people get older, an effect that is related either to comorbidities specific to HIV [37, 38] or to aging [39]. The modest diagnosis-specific cohort effects estimated for MQoL contrast with the fluctuating pattern seen for the effect of age.

The present study was not made without limitations. The first, concerned the naturally upward bias of the outcomes in relation with the original cohorts of diagnosed individuals. This limitation is often found in studies about health-related outcomes as analyses are carried out on data observed among survivors. Indeed, PLWH who died after diagnosis and before the beginning of the survey in 2011 were, unsurprisingly, less healthy than those included in the survey. A second limitation of this study concerns the unrepresentativeness of the ANRS-VESPA2 with respect to the whole population of PLWH in France. Indeed, participants were enrolled directly enrolled in HIV and exclusion criteria were: being unaware of the HIV-positive status; being diagnosed $<6$ months before the survey; being diagnosed $>6$ months before the survey but not receiving medical care for HIV infection; or being diagnosed $>6$ months before the survey but treated either in HIV care units with caseloads under 100 patients or followed up by general practitioners outside hospital care units [25].

To our knowledge, this is the first time that the effects of age and of diagnosis-specific cohort effects on psychosocial and behavioral outcomes of PLWH have been studied simultaneously as explanatory variables. Our results show that the evolution of psychosocial and behavioral outcomes is a complex process which depends on the context which PLWH are exposed to at the time of diagnosis, by developmental characteristics as suggested by the effect of age, and by a combination of both.

\section{Conclusions}

The evolution of PLWH outcomes cannot be completely explained by aging. The clinical and social contexts at the time of HIV diagnosis also play a role. Understanding this evolution may lead to more tailored HIV healthcare policies which take into account different HIV generations and/or different age groups, depending on which psychosocial and behavioral aspects of PLWH need to be improved.

\section{Abbreviations}

EDF: Estimated degrees of freedom; GAM: Generalized additive model; HAART: Highly active antiretroviral therapy; HIV: Human immunodeficiency virus; HRQL: Health-related quality of life; MQoL: Mental quality of life; PLWH: People living with HIV; PQoL: Physical quality of life; QoL: Quality of life; VESPA2: "VIH: Enquête sur les Personnes Atteintes"

\section{Acknowledgements}

We thank all the PLWH who agreed to participate in the ANRS VESPA2 survey, all the members of the different medical staff in participating hospitals, and the community-based organizations AIDES and Act-Up Paris who supported the survey. Finally, we thank Jude Sweeney for the English revision and editing of our manuscript. The authors declare no conflict of interest.

The ANRS VESPA2 Study Group:

France Lert and Bruno Spire (scientific coordinators), Maria Patrizia Carrieri, Rosemary Dray-Spira, Christine Hamelin, Nicolas Lorente, Marie Préau, Marie Suzan-Monti, Fabienne Marcellin and Martin Duracinsky, with the collaboration of Marion Mora and Gwenaëlle Maradan.

Methodological and ground support:

Yann Le Strat (InVS, Saint-Maurice), Lise Cuzin (Hôpital Purpan, Toulouse),

Laurence Meyer (Cesp, Inserm, Le Kremlin Bicêtre), Daniela Rojas-Castro

(Aides, Pantin) and Hugues Fischer (Act-Up Paris).

Data collection:

The ClinSearch firm and the social research institute Ipsos.

Participating hospitals and investigators:

Aix-en-Provence, CH Pays d'Aix (T. Allègre, P. Mours, J.M. Riou, M. Sordage); Angers, CHU Hôtel-Dieu (J.M. Chennebault, P. Fialaire, V. Rabier); Annemasse, CH Alpes-Léman (M. Froidure, D. Huguet, D. Leduc); Avignon, Hôpital Henri Duffaut (G. P ichancourt, A. Wajsbrot); Besançon, Hôpital Saint-Jacques (C. Bourdeaux, A. Foltzer, B. Hoen, L. Hustache-Mathieu); Bobigny, Hôpital Avicenne (S. Abgrall, R. Barruet, O. Bouchaud, A. Chabrol, S. Mattioni, F. Mechai); Bondy, Hôpital Jean Verdier (V. Jeantils); Bordeaux, Hôpital Saint-André (N. Bernard, F. Bonnet, M. Hessamfar, D. Lacoste, D. Malvy, P. Mercié, P. Morlat, F. Paccalin, M.C. Pertusa, T. Pistone, M.C. Receveur, M.A. Vandenhende); Boulogne-Billancourt, Hôpital Ambroise Paré (C. Dupont, A. Freire Maresca, J. Leporrier, E. Rouveix); Caen, Hôpital Clémenceau (S. Dargere, A. de la Blanchardière, A. Martin, V. Noyon, R. Verdon); CH de Chambéry (O. Rogeaux); Clermont-Ferrand, CHU Gabriel Montpied (J. Beytout, F. Gourdon, H. Laurichesse); Colombes, Hôpital Louis-Mourier (F. Meier, E. Mortier, A.M. Simonpoli); Creil, CH Laennec (F. Cordier); Créteil, CHIC (I. Delacroix, V. Garrait, B. Elharrar), Hôpital Henri Mondor (S. Dominguez, A.S. Lascaux, J.D. Lelièvre, Y. Levy, G. Melica); Dijon, Hôpital du Bocage (M. Buisson, L. Piroth, A. Waldner); Eaubonne, Hôpital Simone Veil (N. Gruat, A. Leprêtre); Garches, Hôpital Raymond-Poincaré (P. de Truchis, D. Le Du, J.Cl. Melchior); CH de Gonesse (R. Sehouane, D. Troisvallets); CHU de Grenoble (M. Blanc, I. Boccon-Gibod, A. Bosseray, J.P. Brion, F. Durand, P. Leclercq, F. Marion, P. Pavese); La Rochelle, Hôpital Saint- Louis (E. Brottier-Mancini, L. Faba, M. Roncato-Saberan); La Roche-sur-Yon, CHD Les Oudairies (O. Bollengier-Stragier, J.L. Esnault, S. Leautez-Nainville, P. P erré); CH de Lagny Marne-la-Vallée (E. Froguel, M. Nguessan, P. Simon); Le Chesnay, CH de Versailles (P. Colardelle, J. Doll, C. Godin-Collet, S. Roussin-Bretagne); Le Kremlin-Bicêtre, Hôpital de Bicêtre (J.F. Delfraissy, M. Duracinsky, C. Goujard, D. Peretti, Y. Quertainmont); CH du Mans (J. Marionneau); Lens, CH Dr. Schaffner (E. Aissi, N. Van Grunderbeeck); Limoges, CHU Dupuytren (E. Denes, S. Ducroix-Roubertou, C. Genet, P. 
Weinbreck); Lyon, Hôpital de la Croix-Rousse (C. Augustin-Normand, A. Boibieux, L. Cotte, T. Ferry, J. Koffi, P. Miailhes, T. Perpoint, D. Peyramond, I. Schlienger); Hôpital Édouard-Herriot (J.M. Brunel, E. Carbonnel, P. Chiarello, J.M. Livrozet, D. Makhloufi); Marseille, Hôpital de la Conception (C. Dhiver, H. Husson, A. Madrid, I. Ravaux, M.L. de Severac, M. Thierry Mieg, C. Tomei), Hôpital Nord (S. Hakoun, J. Moreau, S. Mokhtari, M.J. Soavi), Hôpital Sainte Marguerite (O. Faucher, A. Ménard, M. Orticoni, I. Poizot-Martin, M.J. Soavi); Montpellier, Hôpital Gui de Chauliac (N. Atoui, V. Baillat, V. Faucherre, C. Favier, J.M. Jacquet, V. Le Moing, A. Makinson, R. Mansouri, C. Merle); Montivilliers, Hôpital Jacques Monod (N. Elforzli); Nantes, Hôtel-Dieu (C. Allavena, O. Aubry, M. Besnier, E. Billaud, B. Bonnet, S. Bouchez, D. Boutoille, C. Brunet, N. Feuillebois, M. Lefebvre, P. Morineau-Le Houssine, O. Mounoury, P. Point, F. Raffi, V. Reliquet, J.P. Talarmin); Nice, Hôpital I'Archet (C. Ceppi, E. Cua, P. Dellamonica, F. De Salvador-Guillouet, J. Durant, S. Ferrando, V. Mondain-Miton, I. Perbost, S. Pillet, B. Prouvost-Keller, C. Pradier, P. Pugliese, V. Rahelinirina, P.M. Roger, E. Rosenthal, F. Sanderson); Orléans, Hôpital de La Source (L. Hocqueloux, M. Niang, T. Prazuck), Hôpital Porte Madeleine (P. Arsac, M.F. Barrault-Anstett); Paris, Hôpital Bichat - Claude-Bernard (M. Ahouanto, E. Bouvet, G. Castanedo, C. Charlois-Ou, A. Dia Kotuba, Z. Eid-Antoun, C. Jestin, K. Jidar, V. Joly, M.A. Khuong-Josses, N. Landgraf, R. Landman, S. Lariven, A. Leprêtre, F. L'hériteau, M. Machado, S. Matheron, F. Michard, G. Morau, G. Pahlavan, B.C. Phung, M.H. Prévot, C. Rioux, P. Yéni), Hôpital Cochin-Tarnier (F. Bani-Sadr, A. Calboreanu, E. Chakvetadze, D. Salmon, B. Silbermann), Hôpital européen Georges-Pompidou (D. Batisse, M. Beumont, M. Buisson, P. Castiel, J. Derouineau, M. Eliaszewicz, G. Gonzalez, D. Jayle, M. Karmochkine, P. Kousignian, J. Pavie, I. Pierre, L. Weiss), Hôpital Lariboisière (E. Badsi, M. Bendenoun, J. Cervoni, M. Diemer, A. Durel, A. Rami, P. Sellier), Hôpital PitiéSalpêtrière ( $H$. Ait-Mohand, N. Amirat, M. Bonmarchand, F. Bourdillon, G. Breton, F. Caby, J.P. Grivois, C. Katlama, M. Kirstetter, L. Paris, F. Pichon, L. Roudière, L. Schneider, M.C. Samba, S. Seang, A. Simon, H. Stitou, R. Tubiana, M.A. Valantin), Hôpital Saint-Antoine (D. Bollens, J. Bottero, E. Bui, P. Campa, L. Fonquernie, S. Fournier, P.M. Girard, A. Goetschel, H.F. Guyon, K. Lacombe, F. Lallemand, B. Lefebvre, J.L. Maynard, M.C. Meyohas, Z. Ouazene, J. Pacanowski, O. Picard, G. Raguin, P. Roussard, M. Tourneur, J. Tredup, N. Valin); Hôpital Saint-Louis (S. Balkan, F. Clavel, N. Colin de Verdière, N. De Castro, V. de Lastours, S. Ferret, S. Gallien, V. Garrait, L. Gérard, J. Goguel, M. Lafaurie, C. Lascoux-Combe, J.M. Molina, E. Oksenhendler, J. Pavie, C. Pintado, D. Ponscarme, W. Rozenbaum, A. Scemla), Hôpital Tenon (P. Bonnard, L. Lassel, M.G. Lebrette, T. Lyavanc, P. Mariot, R. Missonnier, M. Ohayon, G. Pialoux, M.P. Treilhou, J.P. Vincensini); Hôtel-Dieu (J. Gilquin, B. Hadacek, L. Nait-Ighil, T.H. Nguyen, C. Pintado, A. Sobel, J.P. Viard, O. Zak Dit Zbar); Perpignan, Hôpital Saint-Jean (H. Aumaître, A. Eden, M. Ferreyra, F. Lopez, M. Medus, S. Neuville, M. Saada); Pontoise, CH René Dubos (L. Blum); Quimper, Hôpital Laennec (P. Perfezou); Rennes, Hôpital de Pontchaillou (C. Arvieux, J.M. Chapplain, M. Revest, F. Souala, P. Tattevin); Rouen, Hôpital Charles-Nicolle (S. Bord, F. BorsaLebas, F. Caron, C. Chapuzet, Y. Debab, I. Gueit, M. Etienne, C. Fartoukh, K. Feltgen, C. Joly, S. Robaday-Voisin, P. Suel); Saint-Denis, CH Delafontaine (M.A. Khuong, J. Krausse, M. Poupard, G. Tran Van); Saint-Étienne, CHU Nord (C. Cazorla, F. Daoud, P. Fascia, A. Frésard, C. Guglielminotti, F. Lucht); Strasbourg, Nouvel hôpital civil (C. Bernard-Henry, C. Cheneau, J.M. Lang, E. de Mautort, M. P artisani, M. Priester, D. Rey); Suresnes, Hôpital Foch (C. Majerholc, D. Zucman); Toulon, CHI Chalucet (A. Assi, A. Lafeuillade), Hôpital Sainte-Anne (J.P. de Jaureguiberry, O. Gisserot); Toulouse, Hôpital de La Grave (C. Aquilina, F. Prevoteau du Clary), Hôpital Purpan (M. Alvarez, M. Chauveau, L. Cuzin, P. Delobel, D. Garipuy, E. Labau, B. Marchou, P. Massip, M. Mularczyk, M. Obadia); Tourcoing, CH Gustave Dron (F. Ajana, C. Allienne, V. Baclet, X. de la Tribonnière, T. Huleux, H. Melliez, A. Meybeck, B. Riff, M. Valette, N. Viget); Tours, CHRU Bretonneau (F. Bastides, L. Bernard, G. Gras, P. Guadagnin); Vandoeuvre-lès-Nancy, CHU Brabois (T. May, C. Rabaud); Vannes, CH Bretagne Atlantique (A. Dos Santos, Y. P oinsignon); Villejuif, Hôpital Paul-Brousse, (O. Derradji, L. Escaut, E. Teicher, D. Vittecoq); CHI de Villeneuve-Saint-Georges, (J. Bantsima, P. Caraux-Paz, O. Patey).

\section{Funding}

The VESPA2 survey was sponsored and funded by the French National Agency for Research on Aids and Viral Hepatitis (ANRS).

\section{Availability of data and materials}

The datasets used and/or analyzed during the current study are available from the corresponding author on reasonable request.

\section{Authors' contributions}

The manuscript was written by LST, with input from BS, MS, and RDS. Analyses were carried out by AV and supervised by LST. MM and GM performed data collection under the supervision of VG. All authors approved the final manuscript.

\section{Ethics approval and consent to participate}

The ANRS-VESPA2 survey met the ethical requirements of the French $\mathrm{Na}$ tional Commission for Computing and Liberties (approval number DR-2010368) and received approval from the French Advisory Committee on Information Processing in Material Research in the Field of Health. All the participants provided written informed consent.

\section{Consent for publication}

NA.

\section{Competing interests}

The authors declare that they have no competing interests.

\section{Publisher's Note}

Springer Nature remains neutral with regard to jurisdictional claims in published maps and institutional affiliations.

\section{Author details}

${ }^{1}$ Aix Marseille Univ, INSERM, IRD, SESSTIM, Sciences Economiques \& Sociales de la Santé \& Traitement de l'Information Médicale, 27 Bd Jean Moulin, 13385 Marseille Cedex 5, France. ${ }^{2}$ ORS PACA, Southeastern Health Regional Observatory, 27 Bd Jean Moulin, 13385 Marseille Cedex 5, France. ${ }^{3}$ INSERM, UMR_S1136, Pierre Louis Institute of Epidemiology and Public Health, Team Research in Social Epidemiology, 56, Boulevard Vincent Auriol - CS 81393 75646, F-75013 Paris Cedex 13, France. ${ }^{4}$ Pierre Louis Institute of Epidemiology and Public Health, Team Research in social epidemiology, Sorbonne Universités, UPMC Univ Paris 06, UMR_S1136, 56, Boulevard Vincent Auriol CS 81393 - 75646, F-75013 Paris Cedex 13, France.

\section{Received: 4 October 2018 Accepted: 29 April 2019}

\section{Published online: 17 May 2019}

\section{References}

1. Mouton JP, Cohen K, Maartens G. Key toxicity issues with the WHOrecommended first-line antiretroviral therapy regimen. Expert Rev Clin Pharmacol. 2016;9(11):1493-503.

2. Merlin JS, Zinski A, Norton WE, Ritchie CS, Saag MS, Mugavero MJ, et al. A conceptual framework for understanding chronic pain in patients with HIV. Pain Pract. 2014;14(3):207-16.

3. Emlet CA. "You're awfully old to have this disease": experiences of stigma and ageism in adults 50 years and older living with HIV/AIDS. The Gerontologist. 2006;46(6):781-90.

4. Paolillo EW, Tang B, Depp CA, Rooney AS, Vaida F, Kaufmann CN, et al. Temporal associations between social activity and mood, fatigue, and pain in older adults with HIV: an ecological momentary assessment study. JMIR Ment Health. 5(2) Disponible sur: https://www.ncbi.nlm.nih.gov/pmc/ articles/PMC5972192/. Cité 4 Févr 2019.

5. Crockett KB, Turan B. Moment-to-moment changes in perceived social support and pain for men living with HIV: an experience sampling study. Pain. 2018;159(12):2503-11.

6. Kemppainen JK. Predictors of quality of life in AIDS patients. J Assoc Nurses AIDS Care. 2001;12(1):61-70.

7. Viswanathan $\mathrm{H}$, Anderson R, Thomas J. Nature and correlates of SF-12 physical and mental quality of life components among low-income HIV adults using an HIV service center. Qual Life Res. 2005;14(4):935-44.

8. Nokes KM, Coleman CL, Hamilton MJ, Corless IB, Sefcik E, Kirksey KM, et al. Age-related effects on symptom status and health-related quality of life in persons with HIV/AIDS. Appl Nurs Res. 2011;24(1):10-6.

9. Khumsaen N, Aoup-por W, Thammachak P. Factors influencing quality of life among people living with HIV (PLWH) in Suphanburi Province, Thailand. J Assoc Nurses AIDS Care. 2012;23(1):63-72.

10. Holtz C, Sowell R, VanBrackle L, Velasquez G, Hernandez-Alonso V. A quantitative study of factors influencing quality of life in rural Mexican women diagnosed with HIV. J Assoc Nurses AIDS Care. 2014;25(6):555-67. 
11. Waddell EN, Messeri PA. Social support, disclosure, and use of antiretrovira therapy. AIDS Behav. 2006;10(3):263-72.

12. Hirsch Allen AJ, Forrest JI, Kanters S, O'Brien N, Salters KA, McCandless L, et al. Factors associated with disclosure of HIV status among a cohort of individuals on antiretroviral therapy in British Columbia, Canada. AIDS Behav. 2014;18(6):1014-26.

13. Elopre L, Westfall AO, Mugavero MJ, Zinski A, Burkholder G, Hook EW, et al. Predictors of HIV disclosure in infected persons presenting to establish care. AIDS Behav. 2015; Disponible sur: http://link.springer.com/10.1007/s10461015-1060-8. Cité 26 Oct 2015

14. Lee S, Yamazaki M, Harris DR, Harper GW, Ellen J. Social support and human immunodeficiency virus-status disclosure to friends and family: implications for human immunodeficiency virus-positive youth. J Adolesc Health. 2015;57(1):73-80.

15. Batterham P, Rice E, Rotheram-Borus MJ. Predictors of serostatus disclosure to partners among young people living with HIV in the pre- and postHAART eras. AIDS Behav. 2005;9(3):281-7.

16. Préau M, Marcellin F, Carrieri MP, Lert F, Obadia Y, Spire B, et al. Healthrelated quality of life in French people living with HIV in 2003: results from the national ANRS-EN12-VESPA study. AIDS. 2007;21:S19-27.

17. Douab T, Marcellin F, Vilotitch A, Protopopescu C, Préau M, SuzanMonti $\mathrm{M}$, et al. Health-related quality of life of people living with HIV followed up in hospitals in France: comparing trends and correlates between 2003 and 2011 (ANRS-VESPA and VESPA2 national surveys). AIDS Care. 2014:26(sup1):S29-40.

18. Ocaña-Riola R, Mayoral-Cortés JM, Navarro-Moreno E. Age-period-cohort effect on female breast cancer mortality in southern Spain. Med Oncol. 2013;30(3) Disponible sur: http://link.springer.com/10.1007/s12032-013-0671z. Cité 15 Sept 2015.

19. Alves SM, Castiglione D, Oliveira CM, de Sousa B, Pina MF. Age-periodcohort effects in the incidence of hip fractures: political and economic events are coincident with changes in risk. Osteoporos Int. 2014;25(2): 711-20.

20. Brault M-C, Meuleman B, Bracke P. Depressive symptoms in the Belgian population: disentangling age and cohort effects. Soc Psychiatry Psychiatr Epidemiol. 2012;47(6):903-15.

21. Brown RL, Richman JA, Rospenda KM. Economic stressors and alcoholrelated outcomes: exploring age cohort differences. Addict Behav. 2015;51: 193-6.

22. Pudrovska T. What makes you stronger: age and cohort differences in personal growth after Cancer. J Health Soc Behav. 2010;51(3):260-73.

23. Stockard J, Gray JA, O'Brien R, Stone J. Race differences in cohort effects on non-marital fertility in the United States. Soc Forces. 2009;87(3):1449-79.

24. Jiang B, Carriere KC. Age-period-cohort models using smoothing splines: a generalized additive model approach: B. Jiang and K. C. Carriere. Stat Med. 2014;33(4):595-606.

25. Dray-Spira R, Spire B, Lert F, Groupe V. General method of the ANRS-VESPA2 study [in French]. Bull Epidemiol Hebd. 2013;321(324):283-324.

26. Ware JE Jr, Kosinski M, Keller SD. A 12-item short-form health survey: construction of scales and preliminary tests of reliability and validity. Med Care. 1996;34(3):220-33.

27. Wood SN. Stable and efficient multiple smoothing parameter estimation for generalized additive models. J Am Stat Assoc. 2004;99(467):673-86.

28. R Core Team. R: A language and environment for statistical computing. Vienna: R Foundation for Statistical Computing; 2014. Disponible sur: http:/ www.R-project.org/

29. Wood SN. Fast stable restricted maximum likelihood and margina likelihood estimation of semiparametric generalized linear models. J R Stat Soc Ser B Stat Methodol. 2011;73(1):3-36.

30. Brothers TD, Rockwood K. Biologic aging, frailty, and age-related disease in chronic HIV infection. Curr Opin HIV AIDS. 2014;9(4):412-8.

31. Pathai S, Bajillan H, Landay AL, High KP. Is HIV a model of accelerated or accentuated aging? J Gerontol A Biol Sci Med Sci. 2014;69(7):833-42.

32. Sherr L, Clucas C, Harding R, Sibley E, Catalan J. HIV and depression - a systematic review of interventions. Psychol Health Med. 2011;16(5):493-527.

33. Calcagno A, Nozza S, Muss C, Celesia BM, Carli F, Piconi S, et al. Ageing with HIV: a multidisciplinary review. Infection. 2015;43(5):509-22.

34. Parsons TD, Braaten AJ, Hall CD, Robertson KR. Better quality of life with neuropsychological improvement on HAART. Health Qual Life Outcomes. 2006:4(11):d0i110.
35. Low-Beer S, Chan K, Wood E, Yip B, Montaner JSG, O'shaughnessy M, et al. Health related quality of life among persons with HIV after the use of protease inhibitors. Qual Life Res. 2000;9(8):941-9.

36. Liu C, Weber K, Robison E, Hu Z, Jacobson LP, Gange SJ. Assessing the effect of HAART on change in quality of life among HIV-infected women. AIDS Res Ther. 2006:3(1):6.

37. Warriner AH, Burkholder GA, Overton ET. HIV-related metabolic comorbidities in the current ART era. Infect Dis Clin N Am. 2014;28(3):45776.

38. Petoumenos K, Law M. HIV-infection and comorbidities: a complex mix. Lancet HIV. 2015; Disponible sur: https://www.thelancet.com/journals/ lanhiv/article/PIIS2352-3018(15)00082-X/fulltext. Cité 27 Oct 2015.

39. Onder G, Palmer K, Navickas R, Jurevičienė E, Mammarella F, Strandzheva M, et al. Time to face the challenge of multimorbidity. A European perspective from the joint action on chronic diseases and promoting healthy ageing across the life cycle (JA-CHRODIS). Eur J Intern Med. 2015;26(3):157-9.
Ready to submit your research? Choose BMC and benefit from:

- fast, convenient online submission

- thorough peer review by experienced researchers in your field

- rapid publication on acceptance

- support for research data, including large and complex data types

- gold Open Access which fosters wider collaboration and increased citations

- maximum visibility for your research: over $100 \mathrm{M}$ website views per year

At BMC, research is always in progress.

Learn more biomedcentral.com/submissions 